\title{
SUSCEPTIBILIDADE À CORROSÃO INTERGRANULAR E POR PITES DO AÇO INOXIDÁVEL AUSTENÍTICO AISI 347 SOLDADO E SOLUBILIZADO
}

\author{
Gabriela Paula de Souza' \& Luis Augusto Hernandez Terrones ${ }^{1}$
}

\begin{abstract}
RESUMO
SOUZA, G. P.; TERRONES, L. A. H. Susceptibilidade à Corrosão Intergranular e Por Pites do Aço Inoxidável Austenítico AISI 347 Soldado e Solubilizado. Perspectivas Online: Exatas \& Engenharia, v. 10, n. 29, p. 74-89, 2020.

Nos aços austeníticos, a susceptibilidade ao ataque intergranular é causada pela precipitação de carbetos $\mathrm{Cr}_{23} \mathrm{C}_{6}$ nos contornos de grão em temperaturas entre 480 e $815^{\circ} \mathrm{C}$, que podem ser alcançadas durante as condições de serviço. Adicionalmente, a precipitação de ferrita delta, que surge devido ao ciclo térmico de soldagem, promove a redução da resistência à corrosão por pites. O tratamento térmico de solubilização pode eliminar a precipitação dessas fases, apromovendo um aumeno Neste contexto, esse trabalho contempla uma análise da susceptibilidade à corrosão intergranular e por pites de amostras de aço inoxidável austenítico AISI 347 nas condições: soldado sem tratamento térmico, soldado e solubilizado a $1060^{\circ} \mathrm{C}$ por $27 \mathrm{~min}$ e a $950{ }^{\circ} \mathrm{C}$ por $5 \mathrm{~h}$. Para avaliar a resistência à corrosão, foram realizados: ensaio de susceptibilidade a corrosão intergranular (de acordo com a norma ASTM 262 - 02A) e

acordo com a norma ASTM G48). A caracterização microestrutural foi realizada por meio de microscopia ótica confocal (MO), com posterior quantificação da fração volumétrica dos constituintes presentes de acordo com a norma ASTM E 562-02. Os ensaios mostraram que as amostras solubilizadas após soldagem apresentaram uma redução de $34 \%$ p. na fração de ferrita delta presente na ZF. Observou-se que o material soldado solubilizado a $1060{ }^{\circ} \mathrm{C}$ foi mais susceptível à corrosão intergranular e por pites. Também foi observada a relação entre o acabamento superficial das amostras e a perda de massa: a amostra soldada solubilizada a $950{ }^{\circ} \mathrm{C}$ apresentou a maior perda de massa pois possuía as piores condições de acabamento superficial. Foi concluído que o tratamento térmico de solubilização na temperatura de $950{ }^{\circ} \mathrm{C}$ foi mais efetivo no aumento da resistência à corrosão intergranular e por pites.
\end{abstract} teste de resistência a corrosão por pites (de

$\underline{\text { Palavras-chave: microestrutura, soldagem, tratamento térmico, corrosão }}$

\footnotetext{
${ }^{1}$ Universidade Estadual do Norte Fluminense Darcy Ribeiro - UENF - Laboratório de Materiais Avançados LAMAV/CCT - Av. Alberto Lamego, 2000, Parque Califórnia, Campos dos Goytacazes, RJ, CEP: 28013-602, Brasil. (*) e-mail: gabriela.depaula@ @otmail.com.br
} 


\title{
SUSCEPTIBILITY TO INTERGRANULAR AND PITTING CORROSION OF AISI 347 AUSTENITIC STAINLESS STEEL WELDED AND SOLUTION TREATED
}

\author{
Gabriela Paula de Souza ${ }^{1}$ \& Luis Augusto Hernandez Terrones ${ }^{1}$
}

\begin{abstract}
SOUZA, G. P.; TERRONES, L. A. H. Susceptibility to intergranular and pitting corrosion of AISI 347 austenitic stainless steel welded and solution treated. Perspectivas Online: Exatas \& Engenharia, v. 10, n. 29, p. 74-89, 2020.

The susceptibility to intergranular attack and pitting corrosion in austenitic stainless steels is the result of the sensitization phenomenon, which occurs when these are used at temperatures between $480-815^{\circ} \mathrm{C}$. In this work, was evaluated the susceptibility to intergranular and pitting corrosion of specimens of AISI 347 austenitic stainless steel in the following conditions: welded without heat treatment, welded and solubilized at $1060^{\circ} \mathrm{C}$ for 27 minutes and $950{ }^{\circ} \mathrm{C}$ for 5 hours. To evalue the corrosion resistance, were carried out: intergranular corrosion susceptibility test (according to the ASTM 262 - 02A standard) and pitting corrosion resistance test (according to the ASTM G48 standard). A microstructural characterization consisted of analyzes by confocal optical

micrographs, the volumetric fraction of the components present was quantified according to the ASTM E 562-02 standard. The tests showed that specimens solubilized after welding presented by a $34 \%$ reduction in the fraction of delta ferrite present in the FZ. About susceptibility to intergranular and pitting corrosion, it was observed that the welded material solubilized at $1060{ }^{\circ} \mathrm{C}$ was the most susceptible. The relationship between the surface finish of the samples and the loss of mass was also observed: the welded sample solubilized at $950{ }^{\circ} \mathrm{C}$ showed the greatest loss of mass as it had the worst conditions of surface finish. It was concluded that solubilization heat treatment at temperature of $950{ }^{\circ} \mathrm{C}$ was more effective in increasing resistance to intergranular and pitting corrosion.
\end{abstract} microscopy (OM) and, from the obtained

Keywords: microstructure, welding, heat treatment, corrosion.

\footnotetext{
${ }^{1}$ Northern State University Fluminense Darcy Ribeiro - UENF - Advanced Materials Laboratory LAMAV/CCT - Alberto Lamego Avenue, 2000, Parque Califórnia, Campos dos Goytacazes, RJ, CEP: 28013-602, Brazil.

(*) e-mail: gabriela.depaula@ @otmail.com.br
} 


\section{INTRODUÇÃO}

Aços inoxidáveis austeníticos são amplamente utilizados em indústrias química, de energia, alimentícia, petrolíferas e nuclear por apresentarem bom desempenho mecânico associado à resistência à corrosão em um amplo intervalo de temperaturas (BAI et al., 2014; FUJII et al, 2018; WANG et al., 2019). Devido à sua estrutura cristalina cúbica de face centrada (CFC), podem ser aplicados em temperaturas criogênicas (MALLICK et al., 2017). Embora apresentem boa soldabilidade, podem sofrer sensitização. No aço inoxidável austenítico AISI 304, por exemplo, este fenômeno ocorre quando ele é resfriado lentamente entre $550{ }^{\circ} \mathrm{C}$ e $850{ }^{\circ} \mathrm{C}$ (FONTANA e STAEHLE, 2012). A adição de cromo em teores acima de $11 \%$ em peso, além dos teores de 8 a $20 \%$ em peso de níquel e de 0,03 a $0,1 \%$ em peso de carbono são alguns dos fatores que justificam as propriedades desses aços. (RAJ et al., 2002).

Essa classe de aços constitui a maior família em termos do número de ligas e uso (65 a $70 \%$ da utilização total de aços inoxidáveis) e sua aplicação inclui equipamentos para as indústrias alimentícia, aeroespacial (peças de motor de foguete), ferroviária, naval, petrolífera (trocadores de calor, vasos de pressão, sistemas de exaustão), de celulose e têxtil. A maioria das aplicações dos aços austeníticos requer a utilização em temperaturas elevadas e estes aços tornam-se susceptíveis a corrosão quando submetidos a temperaturas na faixa de 480 - $815{ }^{\circ} \mathrm{C}$, alcançadas nas condições de serviço. Esta susceptibilidade é denominada sensitização e tem sido atribuída a precipitação de carbetos $\mathrm{M}_{23} \mathrm{C}_{6}$ nos contornos de grãos de austenita (ASM HANDBOOK, 1990; RAJ et al., 2002; APERAM, 2015).

Na solidificação dos aços austeníticos o metal líquido contendo $70 \%$ p. de ferro e com diferentes quantidades de cromo e níquel pode se solidificar de diferentes modos: inteiramente como austenita; inicialmente como austenita e posteriormente como ferrita; inicialmente como ferrita e depois como austenita; ou, ainda, inteiramente como ferrita, a medida em que a relação entre os teores de cromo e níquel aumenta. Durante o resfriamento após a solidificação, toda ou parte da ferrita formada anteriormente pode ainda se transformar em austenita, resultando em último caso, em uma microestrutura bifásica com diferentes morfologias (MODENESI, 2001 APUD BROOKS, 1984).

Entre as morfologias de ferrita frequentemente encontradas em aços austeníticos, é importante destacar a presença de ferrita delta, uma fase rica em cromo e pobre em elementos estabilizadores de austenita. Essa fase não é desejável pois sua presença está associada a redução da resistência à corrosão por pites. Adicionalmente, a presença de carbetos $\mathrm{Cr}_{23} \mathrm{C}_{6}$ nos contornos de grãos austeníticos, não é desejável, pois a precipitação desses carbetos nessas regiões promove o empobrecimento de cromo, fazendo com que o aço se torne propenso ao ataque corrosivo intergranular (BADESHIA et al., 2006; SEDRIKS, 1996).

Um dos tratamentos térmicos mais frequentemente especificados para aços inoxidáveis austeníticos antes da sua utilização é o recozimento de solubilização. O principal objetivo deste tratamento, como o nome indica, é dissolver as fases que foram precipitadas durante o processamento termomecânico do material, especialmente os carbetos $\mathrm{Cr}_{23} \mathrm{C}_{6}$. Outro tratamento térmico muito realizado nos aços austeníticos é o recozimento de estabilização, realizado a fim de garantir a máxima resistência à corrosão intergranular. Após o tratamento de recozimento, apenas uma parte do carbono está ligado sob a forma de fases primárias, tais como carbetos $(\mathrm{MC})$, carbonitretos $\mathrm{M}(\mathrm{C}, \mathrm{N})$, nitretos $(\mathrm{MN})$, ou carbosulfetos $\mathrm{M}_{4} \mathrm{C}_{2} \mathrm{~S}_{2}$, onde $\mathrm{M}$ pode ser titânio, nióbio, ou vanádio. $\mathrm{O}$ carbono restante permanece em solução sólida e pode precipitar como carbetos secundários como $\mathrm{M}_{23} \mathrm{C}_{6}$ ou $\mathrm{MC}$ em baixas

Persp. Online: exatas \& eng., Campos dos Goytacazes, 29 (10) $74-89$ - 2020 
temperaturas, uma vez que a solubilidade do carbono na austenita em temperaturas próximas a $900{ }^{\circ} \mathrm{C}$ é muito baixa (TOTTEN, 2006).

Em temperaturas elevadas, entre 480 e $815^{\circ} \mathrm{C}$, que podem ser alcançadas durante as condições de serviço, os aços austeníticos tornam-se susceptíveis a corrosão intergranular e por pites. Nesse contexto, esse trabalho contempla uma análise das caracteristicas microestruturais realizada por meio da quantificação de ferrita delta na microestrutura, além da avaliação da susceptibilidade à corrosão intergranular e por pites do aço inox austenítico AISI 347 nas condições de soldado sem tratamento térmico, soldado e tratado termicamente a $1060{ }^{\circ} \mathrm{C}$ por 27 min e a $950{ }^{\circ} \mathrm{C}$ por $5 \mathrm{~h}$. Dessa forma, os resultados obtidos podem ampliar a possibilidade de utilização desse material em altas temperaturas e em condições agressivas além de recomendar um procedimento alternativo para a realização do tratamento térmico de solubilização em juntas soldadas.

\section{METODOLOGIA}

\subsection{Obtenção e preparação das amostras}

Para realizar este trabalho, foram utilizadas amostras de aço inoxidável austenítico AISI 347 estabilizado ao $\mathrm{Nb}$, fornecido na forma de chapas soldadas. A soldagem das chapas foi realizada com o processo TIG automático no passe de raiz e para o passes de enchimento e acabamento foi utilizado o processo de soldagem por arco plasma em junta de topo com chanfro "V" simples. A Tabela 1 mostra a composição química do aço e do metal de adição. A partir das chapas foram cortadas barras retangulares perpendiculares ao cordão de solda, com dimensões de 13 x $105 \mathrm{~mm}$ de comprimento. O corte foi realizado no cortador mecânico Mesotom, com refrigeração e disco de óxido de alumínio. Após o corte não foi necessário embutir as amostras porque as dimensões da superfície de análise eram suficientemente grandes. As amostras foram lixadas com lixas de granulometrias 100, 220, 400, 600, 1200\# (mesh). Após o lixamento, executou-se polimento mecânico utilizando alumina de granulometria de $1 \mu \mathrm{m}$ e posteriormente $0,3 \mu \mathrm{m}$ e, posteriormente, as amostras foram atacadas eletroliticamente com uma solução de ácido oxálico $10 \%$ à uma tensão de $2 \mathrm{~V}$ e corrente de 0,23 A em um tempo médio de 3 minutos para cada amostra.

Tabela 1: Composição química do aço e do metal de adição.

\begin{tabular}{ccccccccccc}
\hline & C & Mn & Si & Cr & Ni & Mo & P & S & Nb & Cu \\
\hline AISI 347 & 0,015 & 1,89 & 0,44 & 17,06 & 10,1 & 0,33 & 0,015 & 0,002 & 0,66 & - \\
& & & & & & & & & & \\
\hline ER308L & 0,015 & 1,85 & 0,48 & 20 & 10,1 & 0,50 & 0,015 & 0,010 & $<0,60$ & $<0,20$
\end{tabular}

\subsection{Condições das Amostras}

Foram analisadas três amostras, uma de cada condição:

1. Como recebida: amostra soldada sem tratamento térmico de solubilização.

2. Como recebida: solubilização à $1060^{\circ} \mathrm{C}$ por 27 minutos e resfriamento ao ar.

3. Solubilização à $950{ }^{\circ} \mathrm{C}$ por $5 \mathrm{~h}$ e resfriamento em água. Esse tratamento térmico foi

Persp. Online: exatas \& eng., Campos dos Goytacazes, 29 (10) 74 - 89 - 2020

https://ojs3.perspectivasonline.com.br/ 
realizado no LAMAV/UENF em forno mufla da marca INTI, modelo FL-1300, com taxa de aquecimento de $10^{\circ} \mathrm{C} / \mathrm{min}$.

Na Tabela 2 são apresentados os tratamento térmicos e a identificação correspondente das amostras:

Tabela 2: Tipo de tratamento e identificação correspondentes à cada condição das amostras.

\begin{tabular}{|c|c|}
\hline Identificação da amostra & Condição \\
\hline $1060^{\circ} \mathrm{C}$ & $\begin{array}{c}\text { Solubilizada por } 27 \text { minutos a } 1060^{\circ} \mathrm{C} \text { após } \\
\text { soldagem }\end{array}$ \\
\hline $950^{\circ} \mathrm{C}$ & $\begin{array}{c}\text { Solubilizada a } 950{ }^{\circ} \mathrm{C} \text { por } 5 \text { horas após } \\
\text { soldagem }\end{array}$ \\
\hline ST & Sem tratamento após soldagem \\
\hline
\end{tabular}

\subsection{Análise Microestrutural e Identificação de Fases}

Para analisar a microestrutura das amostras nas diferentes condições e para a quantificar a ferrita delta formada após o tratamento de solubilização, foram obtidas micrografias da microestrutura das amostras, com aumento de $1075 \mathrm{X}$, por meio do microscópio confocal OLYMPUS LEXT OLS4000. Micrografias de diferentes regiões da zona fundida $(\mathrm{ZF})$, zona termicamente afetada (ZTA) e metal base (MB) foram obtidas.

\subsection{Metalografia Quantitativa}

A fração volumétrica dos constituíntes presentes foi quantificada de acordo com a norma ASTM E 562-02 que descreve um procedimento de contagem manual de pontos para estimar a porcentagem estatística de volume de uma fase a partir da microestrutura, por meio de uma grade de pontos. No método da contagem de pontos, observa-se a quantidade de pontos que se localizam em um determinado constituinte em relação a totalidade de pontos $\mathrm{P}$ traçados, conforme mostrado na Figura 1. A quantificação foi realizada na ZF, na ZTA e no MB para o material em cada condição: sem tratamento térmico, solubilizado a $1060{ }^{\circ} \mathrm{C}$ por 27 minutos e solubilizado a $950{ }^{\circ} \mathrm{C}$ por 5 h. Foram utilizadas 5 micrografias aleatórias de cada região das amostras com o aumento de 1075 X. Ao todo, foi realizada a quantificação em 45 micrografias.

Persp. Online: exatas \& eng., Campos dos Goytacazes, 29 (10) $74-89-2020$ 


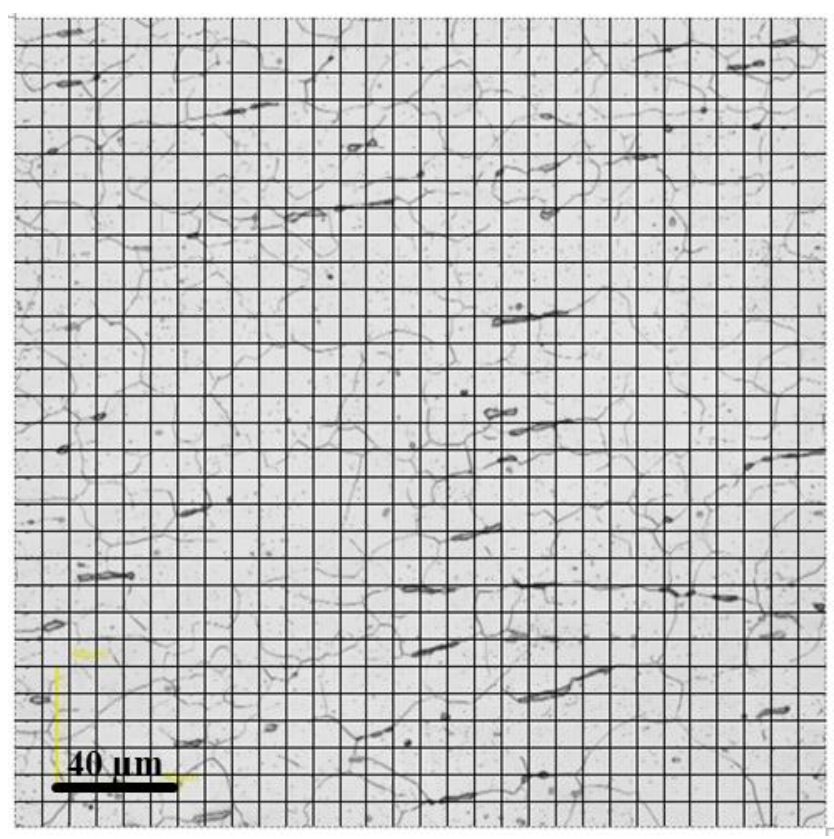

Figura 1: Método de contagem manual de pontos de acordo com a norma ASTM E $562-02$.

A quantidade percentual de ferrita delta presente foi calculada com a equação 1:

$$
\% \text { fase }=\frac{n}{P}
$$

Onde:

n: número de pontos correspondente a determinada fase;

P: número total de pontos ( 5 micrografias $\mathrm{x} 841$ pontos de cada reticulado $=4205$ pontos).

\subsection{Ensaio de Susceptibilidade a Corrosão}

\subsubsection{Ataque com Ácido Oxálico: classificação das estruturas de corrosão}

Um segundo ataque eletrolítico foi realizado nas amostras de modo a superatacá-las para determinar as estruturas de corrosão de acordo com a norma ASTM 262 - 02A, que descreve os procedimentos e apresenta micrografias para a identificação da susceptibilidade ao ataque intergranular de aços inoxidáveis austeníticos. Uma amostra susceptível à corrosão terá precipitação de carbetos de cromo nos contornos de grão, com aspecto de "valas", cuja estrutura é classificada como "ditch". Nessa análise, utilizou-se a prática A - ataque com ácido oxálico $10 \%$ para classificação das estruturas de corrosão em aços inoxidáveis austeníticos. As amostras foram super atacadas em um tempo médio de 5 minutos à uma tensão de $2 \mathrm{~V}$ e corrente de 0,35 A. Após o superataque, as amostras foram analisadas no microscópio confocal OLYMPUS LEXT OLS4000 para obtenção das micrografias da ZF. ZTA e MB.

Persp. Online: exatas \& eng., Campos dos Goytacazes, 29 (10) $74-89-2020$ 


\subsection{Teste de Resistência à Corrosão por Pites}

O teste de resistência à corrosão por pites seguiu a norma ASTM G48, que descreve métodos para comparar a resistência à corrosão por pites em aços inoxidáveis em meios contendo cloretos. Para o estudo das amostras, foi utilizado o Método A - teste de corrosão por pites com cloreto férrico.

Antes do teste, as amostras foram lixadas com lixas de 600 e 1200 mesh, e em seguida, polidas com alumina de granulometria de $1 \mu \mathrm{m}$. Após o polimento as amostras foram limpas em ultrassom e secas em álcool etílico e posteriormente pesadas em balança analítica marca sartorius, modelo TE214S com precisão de $0,0001 \mathrm{~g}$.

O procedimento experimental consistiu em colocar $600 \mathrm{~mL}$ de solução de cloreto férrico $\left(\mathrm{FeCl}_{3}\right)$ num Becker de $1000 \mathrm{~mL}$, respeitando a relação volume de solução por área superficial da amostra, que deve ser de no mínimo $5 \mathrm{~mL} / \mathrm{cm}^{2}$. O Becker com as amostras foi mantido em uma temperatura constante (a norma recomenda a temperatura de $22^{\circ}+/-2{ }^{\circ} \mathrm{C}$ ou $50^{\circ}+/-2{ }^{\circ} \mathrm{C}$ para avaliação). Durante o experimento foi utilizada a temperatura ambiente $\left(25^{\circ} \mathrm{C} \pm 2{ }^{\circ} \mathrm{C}\right)$.

O tempo do ensaio foi de $72 \mathrm{~h}$. Após o término do ensaio as amostras foram devidamente limpas em água corrente com o auxílio de uma escova de náilon de cerdas finas para remover produtos de corrosão. Após a limpeza, as amostras foram secas em acetona e pesadas novamente.

As amostras foram analisadas no microscópio confocal OLYMPUS LEXT OLS4000 para obtenção das imagens dos pites. Também foram realizados exames para avaliar a perda de massa e densidade de pites na superfície polida a fim de caracterizar a resistência a corrosão por pites.

\section{RESULTADOS E DISCUSSÃO}

A Figura 2 mostra a macrografia do material estudado.

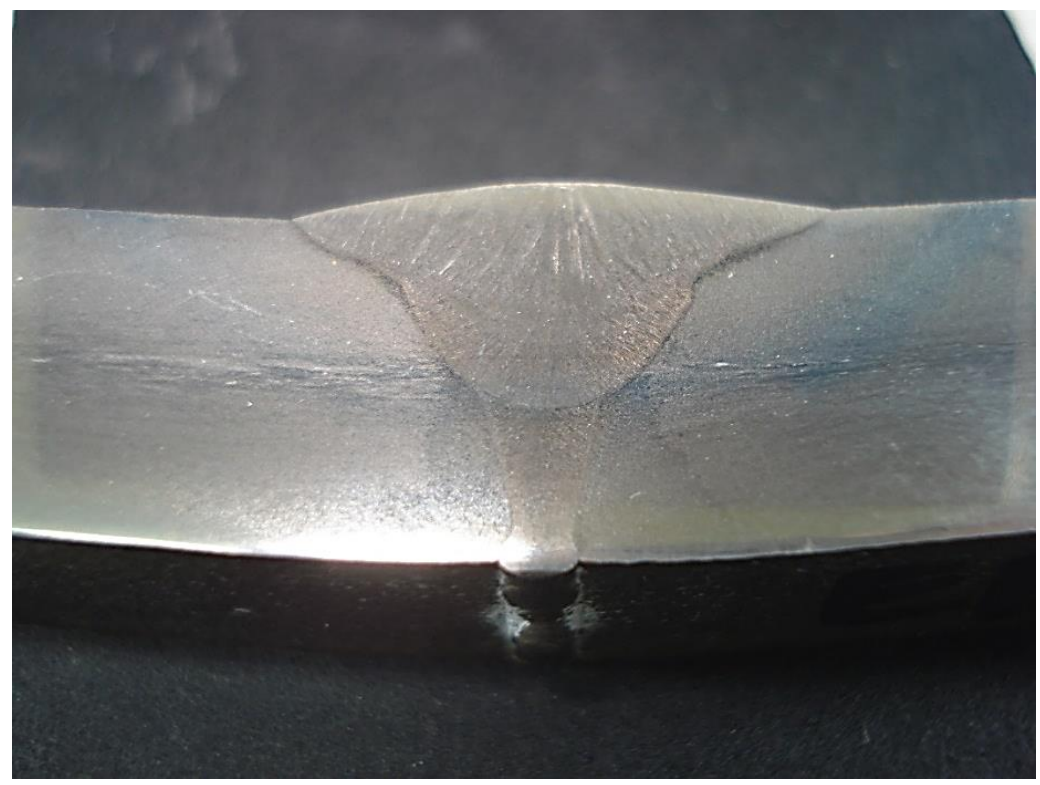

Figura 2: Macrografia do aço AISI 347 soldado.

Persp. Online: exatas \& eng., Campos dos Goytacazes, 29 (10) $74-89-2020$ https://ojs3.perspectivasonline.com.br/ 


\subsection{Caracterização Microestrutural}

As Figuras 3, 4 e 5 mostram em a) a microestrutura da zona fundida (ZF), b) a zona termicamente afetada (ZTA) e c) o metal base (MB) para as amostras das três condições estudadas.

\subsubsection{Amostra sem tratamento}

Na Figura 3 a) é possível observar uma ZF com microestrutura composta de ferrita delta vermicular, ferrita laminar e ferrita delta poligonal intragranular em uma matriz austenítica. De acordo com a Figura 3 b), a ZTA apresenta predominância de ferrita delta de contorno de grão e ferrita delta poligonal intragranular. Na figura $3 \mathrm{c}$ ), a microestrutura do MB apresenta precipitados localizados no interior dos grãos austeníticos, além de ferrita delta de contorno de grão alongada e ferrita delta poligonal intragranular, com morfologia esférica.

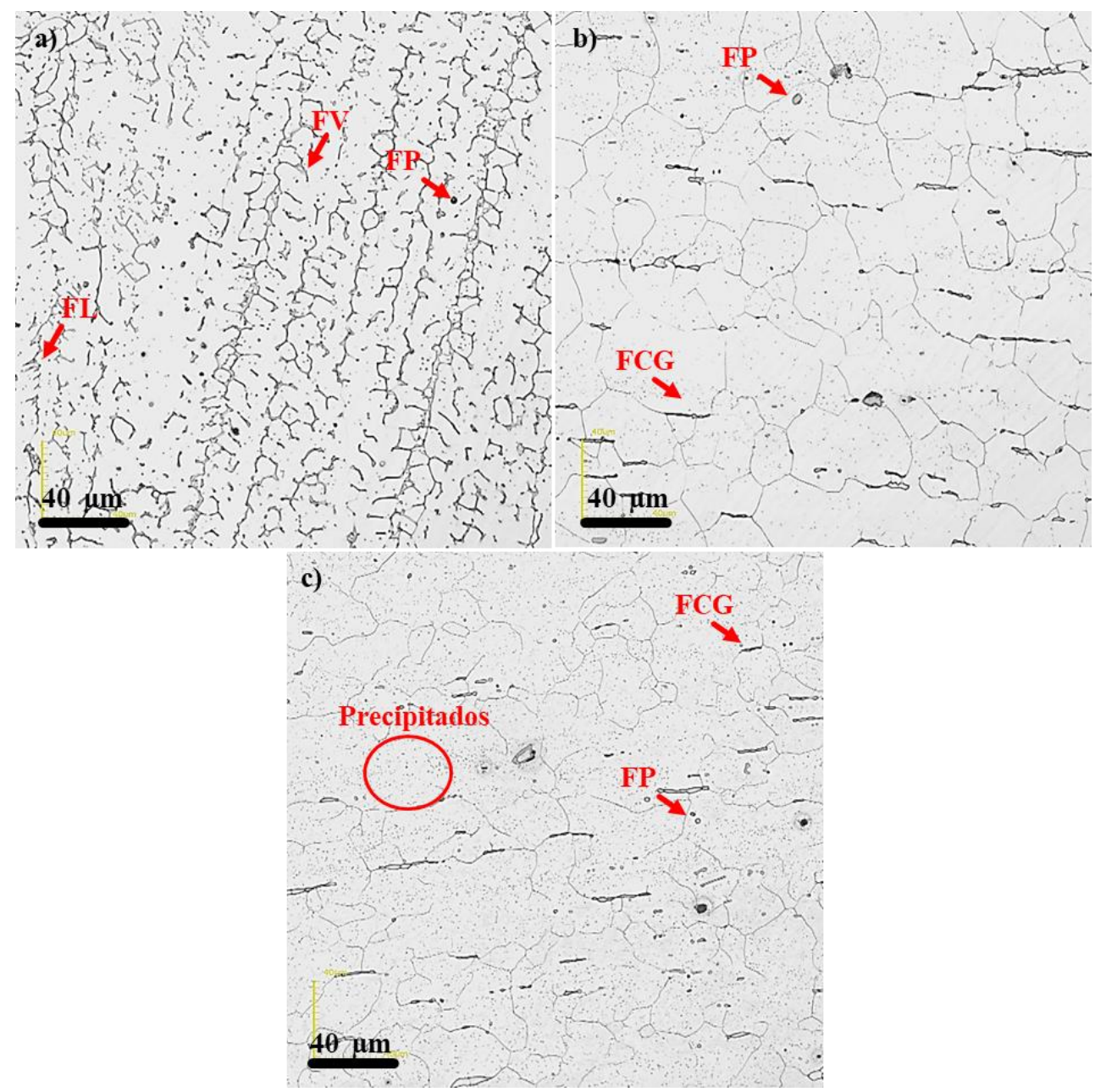

Figura 3: Micrografias da a) ZF b) ZTA c) MB

A ferrita delta vermicular (FV) é formada no final da solidificação e apresenta-se na forma mais espaçada, sendo o tipo de morfologia mais observada no resfriamento rápido de soldas de aços inoxidáveis. Na ferrita delta laminar (FL), a austenita aparece na forma de lâminas aproximadamente paralelas, com a ferrita remanescente localizada entre as lâminas. Adicionalmente, a ferrita delta poligonal (FP) apresenta-se sob forma aproximadamente esférica, em pouca quantidade (MODENESI, 2001; BADESHIA, 2006). Em relação à formação da ferrita delta de contorno de grão (FCG), essa é controlada pela razão entre a

Persp. Online: exatas \& eng., Campos dos Goytacazes, 29 (10) $74-89-2020$

https://ojs3.perspectivasonline.com.br/ 
porcentagem de $\mathrm{Cr}$ e Ni presentes na liga, quanto maior for a razão entre esses elementos, mais provável será sua formação (LIPPOLD et al., 2005).

\subsubsection{Amostra solubilizada a $1060{ }^{\circ} \mathrm{C}$ por 27 minutos}

A Figura 4 a) mostra a microestrutura da ZF da amostra, com presença de ferrita delta poligonal intragranular com morfologia esférica, ferrita delta de contorno de grão e de ferrita delta laminar. A ZTA mostrada na Figura 4 b) apresenta microestrutura austenítica de grãos equiaxiais e maclas, com pequena quantidade de ferrita delta poligonal intragranular e de contorno de grão. O MB mostrado na Figura 4 c) apresenta ferrita delta de contorno de grão alongada, ferrita delta poligonal intragranular além da presença de finos precipitados dispersos no interior dos grãos austeníticos.
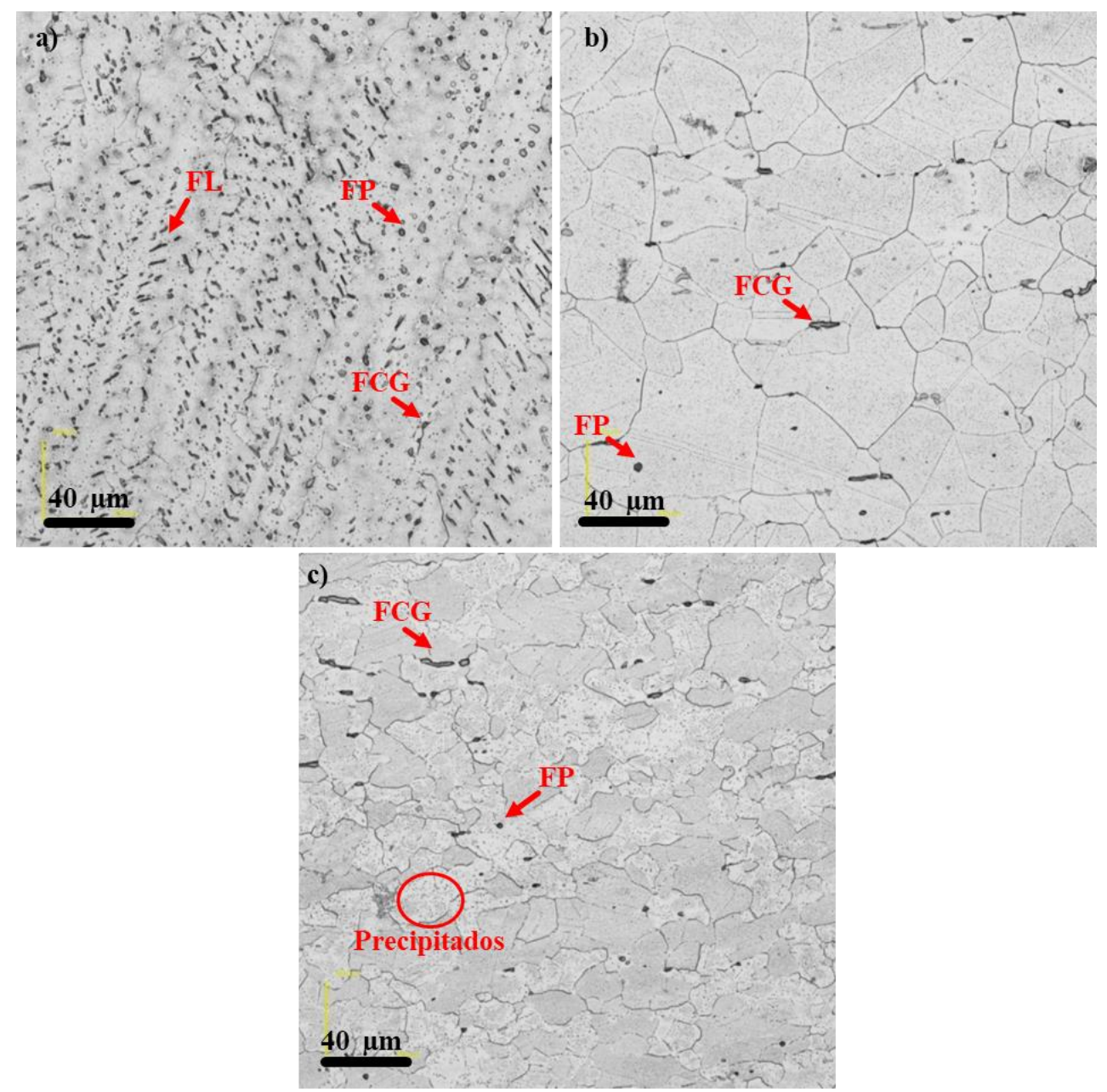

Figura 4: Micrografias da a) ZF b) ZTA c) MB

Nas micrografias é possível observar que, mesmo com tratamento térmico de solubilização a $1060{ }^{\circ} \mathrm{C}$ por $27 \mathrm{~min}$, os precipitados continuam presentes na matriz austenítica.

Persp. Online: exatas \& eng., Campos dos Goytacazes, 29 (10) $74-89-2020$

https://ojs3.perspectivasonline.com.br/ 


\subsubsection{Amostra solubilizada a $950{ }^{\circ} \mathrm{C}$ por 5 horas}

Na micrografia da Figura 5 a) a microestrutura da ZF da amostra apresenta ferrita delta de contorno de grão, ferrita delta poligonal e laminar. As Figuras 5 b) e 5 c) da ZTA e do MB respectivamente, apresentam ferrita delta de contorno de grão com morfologia alongada e ferrita delta poligonal intragranular.

Na comparação entre as figuras 3 a) e 5 a) é possível observar na ZF da amostra sem tratamento a ferrita predominante é a vermicular, de modo diferente da $\mathrm{ZF}$ da amostra solubilizada a $950{ }^{\circ} \mathrm{C}$, que apresenta ferrita de contorno de grão e poligonal.

Adicionalmente, pode-se observar que a solubilição à $950{ }^{\circ} \mathrm{C}$ por $5 \mathrm{~h}$ provocou a dissolução dos precipitados da matriz austenítica, presentes nas amostras das condições anteriores.

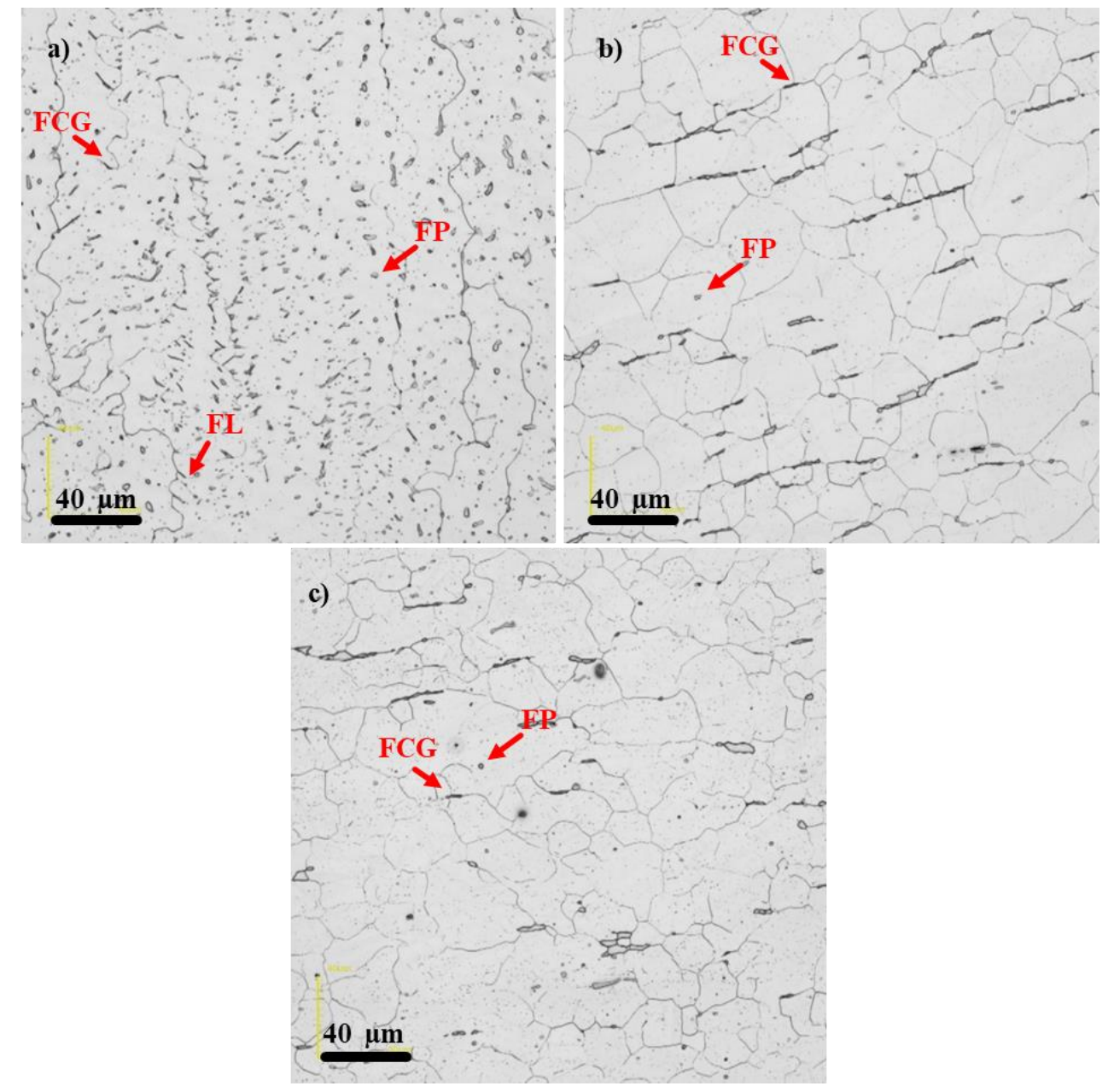

Figura 5: Micrografias da a) ZF b) ZTA c) MB

Persp. Online: exatas \& eng., Campos dos Goytacazes, 29 (10) 74 - 89 - 2020

https://ojs3.perspectivasonline.com.br/ 
De forma geral, para as três condições estudadas, é possível perceber que o tratamento térmico de solubilização promoveu alteração na morfologia de ferrita delta apenas na ZF.

A Tabela 3 mostra a média e o desvio padrão da porcentagem de ferrita delta nas micrografias e a Figura 6 mostra um gráfico comparativo das porcentagens médias de ferrita delta da ZF, ZTA e MB das amostras:

Tabela 3: Média e desvio padrão da porcentagem de ferrita delta nas micrografias para cada região analisada das amostras.

\begin{tabular}{cccc}
\hline & \% & Ferrita $\delta$ & Média e Desvio Padrão \\
& ST & $\mathbf{1 0 6 0}{ }^{\circ} \mathbf{C ~ 2 7}$ min & $\mathbf{9 5 0}^{\circ} \mathbf{C ~ 5 h}$ \\
\hline ZF & $10,4 \pm 1,2$ & $6,6 \pm 2,6$ & $6,2 \pm 2,3$ \\
ZTA & $2,0 \pm 1,1$ & $2,0 \pm 0,7$ & $2,1 \pm 0,6$ \\
MB & $1,3 \pm 0,5$ & $1,3 \pm 0,5$ & $1,4 \pm 0,9$ \\
\hline
\end{tabular}

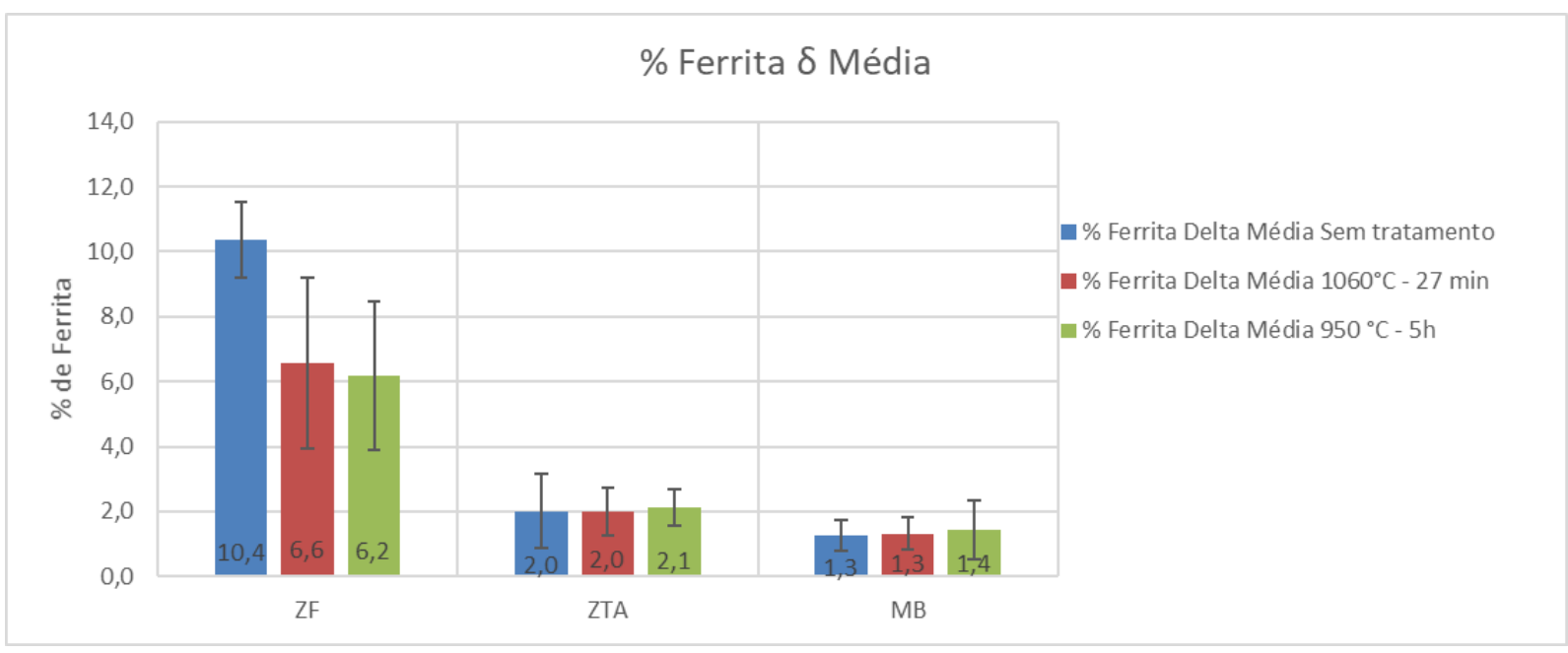

Figura 6: Comparação das porcentagens de ferrita delta média nas micrografias para as três condições estudadas.

Por meio de da análise do gráfico apresentado na Tabela 3 e da Figura 6 é possível observar que nas três condições, a fração de ferrita delta diminuiu entre a ZF, ZTA e MB, sendo a redução na fração desse constituinte pouco expressiva na ZTA e no MB. Desse modo, para as três condições estudadas, os tratamentos térmicos de solubilização reduziram o teor de ferrita delta apenas na ZF.

Nas amostras tradadas houve redução do teor de ferrita delta em cerca de $34 \%$ v. em relação à amostra sem tratamento. A redução no teor dessa fase é explicada pelo fato dessa ser dissolvida nas temperaturas do tratamento térmico de solubilização. A recomendação para realização de tratamento térmico de solubilização pós soldagem tem como objetivo dissolver parte da ferrita e evitar a precipitação de carbetos do tipo $\mathrm{M}_{23} \mathrm{C}_{6}$. Desta forma, os aços inoxidáveis austeníticos estabilizados ao $\mathrm{Nb}$, por exemplo o AISI 347, podem ser utilizados em elevadas temperaturas de serviço (TAVARES et al., 2008).

Priceputu et al. (2011), promoveu o estudo da influência do teor de ferrita delta em aço austenítico AISI 321 e constatou que um teor de ferrita delta de no máximo $8 \%$ em aços inoxidáveis austeníticos soldados é aceitável sem causar problemas. Teores dentro desse

Persp. Online: exatas \& eng., Campos dos Goytacazes, 29 (10) 74 - 89 - 2020

https://ojs3.perspectivasonline.com.br/ 
limite melhoram a resistência ao craqueamento do metal soldado e melhoram a resistência à fratura. Em proporções maiores do que $10 \%$, e em longos períodos de exposição, a ferrita delta pode ser prejudicial para a zona fundida, devido a transformação em fase sigma (frágil e quebradiça).

\subsection{Susceptibilidade à Corrosão Intergranular}

Com base na norma ASTM A262-02A, que disponibiliza uma série de micrografias e a classificação destas em estruturas susceptíveis ou não à corrosão intergranular, as Figuras 7, 8 e 9 apresentam as estruturas de corrosão das amostras.
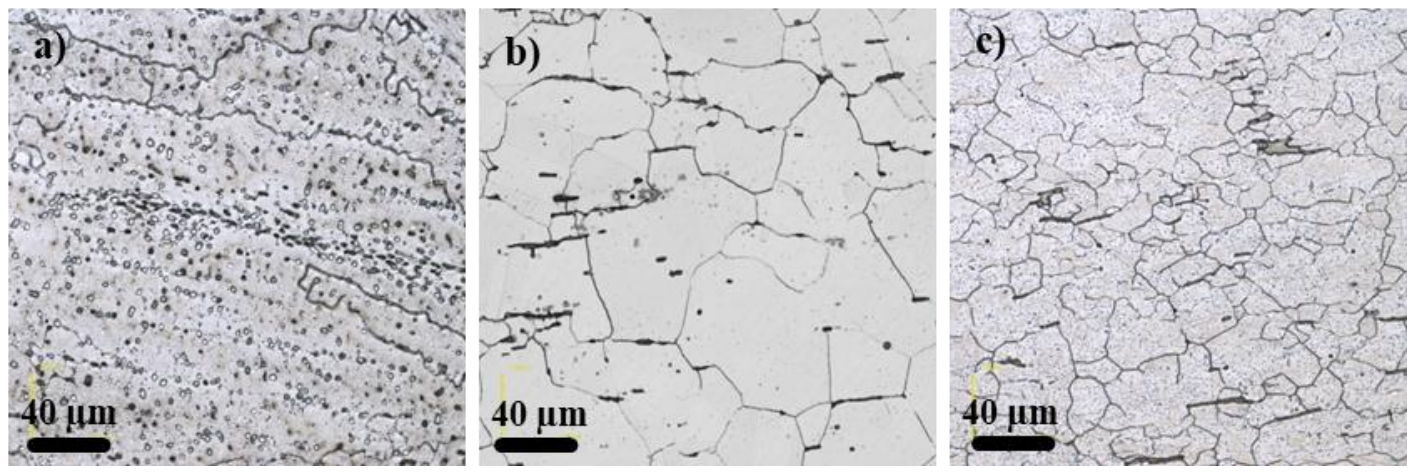

Figura 7: Micrografias da amostra sem tratamento após superataque: a) ZF b) ZTA c) MB.
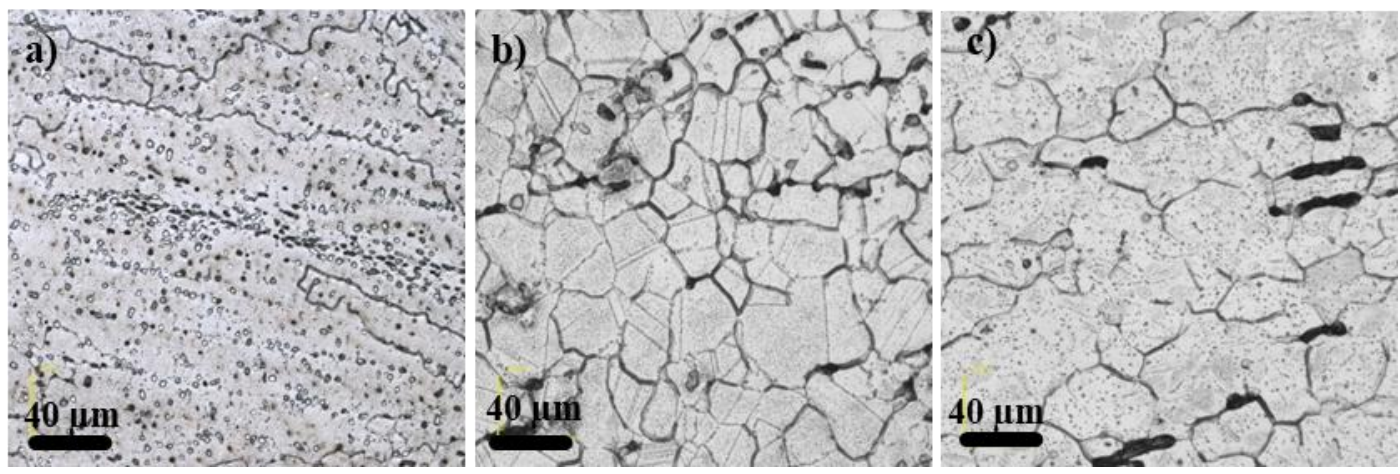

Figura 8: Microestruturas da amostra solubilizada a $1060{ }^{\circ} \mathrm{C}$ por 27 min. após superataque: a) ZF b) ZTA c) MB.
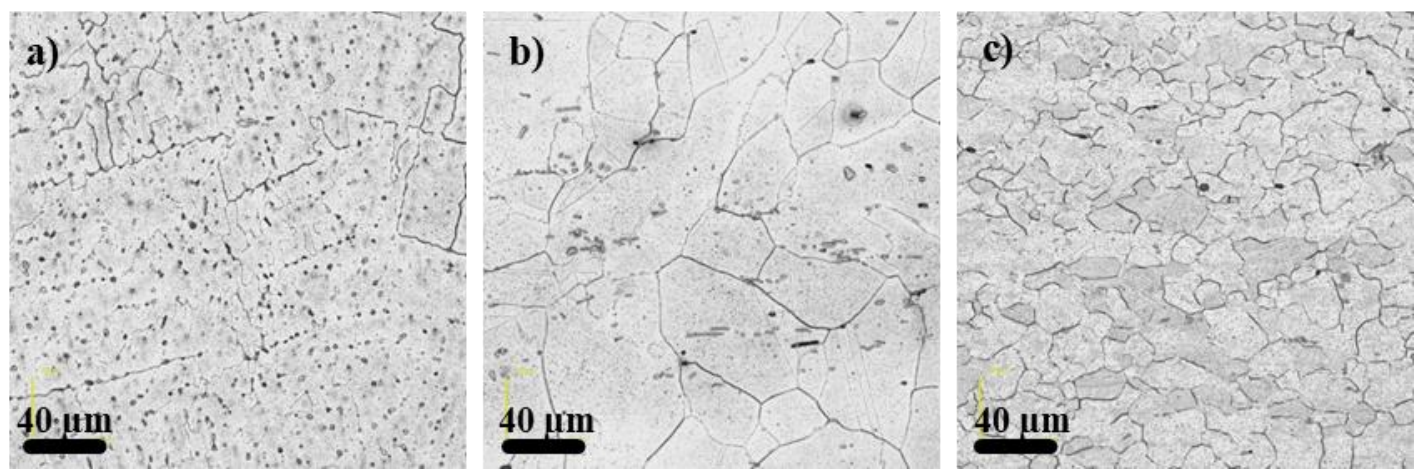

Figura 9: Microestruturas da amostra solubilizada a $950{ }^{\circ} \mathrm{C}$ por $5 \mathrm{~h}$ após superataque: a) ZF b) ZTA c) MB.

Persp. Online: exatas \& eng., Campos dos Goytacazes, 29 (10) $74-89-2020$ https://ojs3.perspectivasonline.com.br/ 
As micrografias da Figura 7 mostram que na ZF e MB da amostra sem tratamento, as estruturas são classificadas como "ditch" (contornos de grão com a aparência de "valas", completamente cercados por carbetos), enquanto a estrutura da ZTA é classificada como "step" (degraus sem a presença de carbetos nos contornos de grão). A Figura 8 mostra que a estrutura de corrosão "ditch" aparece em todas as zonas da amostra solubilizada à $1060{ }^{\circ} \mathrm{C}$ por $27 \mathrm{~min}$. De acordo com a ASTM A262-02A, nessa condição a amostra é completamente susceptível ao ataque intergranular, uma vez que todas estruturas de corrosão foram classificadas como "ditch".

Por meio da análise das micrografias da Figura 9, para a amostra solubilizada a $950{ }^{\circ} \mathrm{C}$ por $5 \mathrm{~h}$, a estrutura de corrosão da ZF é classificada como "dual" (alguns pontos onde os carbetos circundam o grão mas sem envolvê-lo completamente). A estrutura da ZTA é classificada como "step", enquanto a do MB é classificada como "ditch". Esse tratamento provocou a dissolução dos precipitados da matriz austenítica, associados à susceptibilidade à corrosão intergranular. Quando se compara aços estabilizados sem tratamento de solubilização com aços estabilizados após solubilização, a susceptibilidade neste último é significativamente menor (TAVARES ET AL 2008 ; GONÇALVES et al., 2016).

De acordo com Gonzaga et al (2020), em seu estudo sobre a influência dos tratamentos térmicos pós-soldagem na sensitização do aço inoxidável AISI 347, em amostras soldadas sem tratamento térmico pós soldagem, os ensaios de susceptibilidade à corrosão intergranular mostraram uma microestrutura com aspecto "ditch", provocado pela precipitação de carbetos do tipo $\mathrm{M}_{23} \mathrm{C}_{6}$. Nesse caso, para prevenir o ataque intergranular, recomenda-se o solubilização de toda a peça soldada seguida de estabilização local, ou apenas a aplicação de estabilização local.

\subsection{Ensaio de Resistência à Corrosão por Pites}

Para as amostras nas três condições estudadas, a Figura 10 apresenta as macrografias e a Tabela 5 apresenta os resultados obtidos após o ensaio de corrosão por pites.

A Figura 10 a) e c) apresenta a macrografias da amostra soldada sem tratamento e soldada solubilizada a $950{ }^{\circ} \mathrm{C}$ e nelas é possível perceber que essas amostras apresentaram poucos pites na superfície polida e, consequentemente, menor densidade de pites, conforme mostrado na Tabela 4. Nessas amostras a corrosão não foi acentuada pois, provavelmente, a camada passiva formada pelo cromo não possuía aberturas, o que impediu o ataque localizado pelos íons de cloro provenientes da solução de $\mathrm{FeCl}_{3}$.

A Figura 10 b) mostra a macrografia da amostra soldada solubilizada a $1060{ }^{\circ} \mathrm{C}$, que apresentou maior quantidade de pites na face polida e consequentemente a maior densidade de pites entre as três amostras analisadas. Os pites estavam concentrados principalmente na zona termicamente afetada e no metal base. Acredita-se que essa quantidade de pites foi influenciada pelo resfriamento ao ar após o tratamento térmico. De acordo com ASM Handbook Vol. 1 (1990), no resfriamento ao ar, o material permanece por maior quantidade de tempo em uma mesma temperatura e, de acordo com o diagrama TTT do aço austenítico 347 , na temperatura de $650{ }^{\circ} \mathrm{C}$ há maior precipitação de carbetos do tipo $\mathrm{Cr} 23 \mathrm{C}$. Esses carbetos quando preciptados, são responsáveis por empobrecer as regiões adjacentes em $\mathrm{Cr}$ e assim geram aberturas na camada passiva que são responsáveis pelo ataque localizado.

Em relação a perda de massa das amostras, a Tabela 4 evidencia que a amostra solubilizada a $950{ }^{\circ} \mathrm{C}$ apresentou a maior perda de massa. De acordo com a norma ASTM G48, em amostras com superfícies irregulares e em condições de péssimo acabamento superficial, a corrosão por pites é facilitada. A amostra solubilizada a $950{ }^{\circ} \mathrm{C}$ possuía as piores condições de acabamento superficial das faces não polidas. Em relação as amostras soldada sem tratamento e

Persp. Online: exatas \& eng., Campos dos Goytacazes, 29 (10) $74-89-2020$ 
solubilizada a $1060{ }^{\circ} \mathrm{C}$, estas possuíam as melhores condições de acabamento superficial, justificando a menor perda de massa.

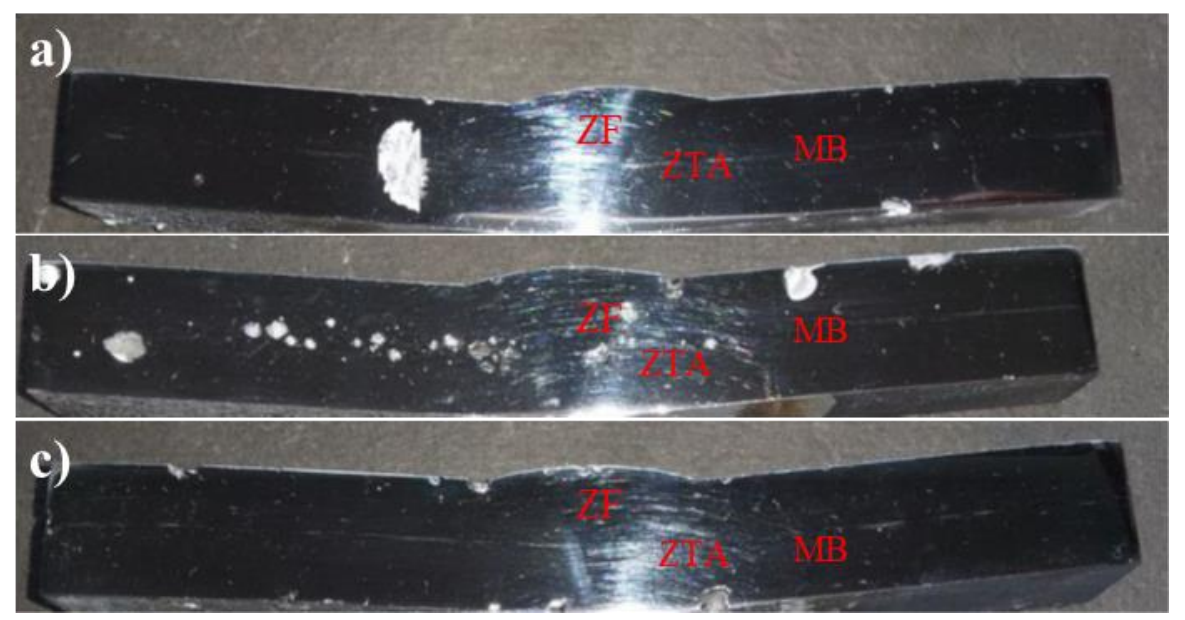

Figura 10: Macrografia das amostras: a) sem tratamento, b) solubilizada a $1060{ }^{\circ} \mathrm{C}$ e c) solubilizada a $950{ }^{\circ} \mathrm{C}$.

Tabela 4: Resultados do ensaio de corrosão por pites.

\begin{tabular}{ccc}
\hline Amostra & $\begin{array}{c}\text { Densidade de Pites na } \\
\text { Face Polida }\left(\text { pites } / \mathbf{m m}^{2}\right)^{*}\end{array}$ & Perda de Massa $(\mathbf{g}) * *$ \\
\hline $\mathrm{ST}$ & 0,015 & 3,054 \\
$1060{ }^{\circ} \mathrm{C}$ & 0,308 & 2,855 \\
$950{ }^{\circ} \mathrm{C}$ & 0,041 & 4,434 \\
\hline
\end{tabular}

\footnotetext{
*Cálculo de densidade de pites: considerada apenas a face polida da amostra.

**Cálculo da perda de massa: todas as faces foram consideradas.
}

\section{CONCLUSÕES}

1. O tratamento térmico de solubilização nas temperaturas de $1060{ }^{\circ} \mathrm{C}$ e $950{ }^{\circ} \mathrm{C}$ alterou a morfologia e reduziu a porcentagem de ferrita delta em cerca de $34 \%$ nas amostras solubilizadas; esse valor está dentro do limite aceitável para que não haja redução das propriedades da zona fundida.

2. Nas amostras soldadas solubilizadas a $1060{ }^{\circ} \mathrm{C}$ e a $950{ }^{\circ} \mathrm{C}$, a temperatura e o tempo de tratamento não provocaram diferenças significativas entre as morfologias e a porcentagem de ferrita delta.

3. No ensaio de susceptibilidade a corrosão intergranular, a amostra solubilizada a $1060^{\circ} \mathrm{C}$ foi mais propensa ao ataque intergranular.

4. De acordo com os resultados do ensaio de corrosão por pites, pode-se concluir que

Persp. Online: exatas \& eng., Campos dos Goytacazes, 29 (10) $74-89-2020$

https://ojs3.perspectivasonline.com.br/ 
a amostra solubilizada a $1060{ }^{\circ} \mathrm{C}$ foi mais propensa ao ataque localizado na superfície polida. Essa amostra foi submetida a resfriamento lento após o tratamento térmico de solubilização, o que causou maior precipitação de carbetos de cromo responsáveis pelo ataque localizado.

5. A amostra solubilizada a $950{ }^{\circ} \mathrm{C}$ apresentou a maior perda de massa entre as amostras analisadas pois apresentava as piores condições de acabamento superficial. Nesse caso, conclui-se que o acabamento superficial da amostra exerce grande influência na resistência à corrosão por pites.

6. O tratamento térmico de solubilização na temperatura de $950{ }^{\circ} \mathrm{C}$ foi mais efetivo no aumento da resistência à corrosão intergranular e por pites.

\section{REFERÊNCIAS}

ASM HANDBOOK. Properties and Selection: Irons, Steels, and High-Performance Alloys. Vol. 1. ASM Internacional, 1990. EUA

ASTM A262. Standard Practices for Detecting Susceptibility to Intergranular Attack in Austenitic Stainless Steels, ASTM International, 2008. West Conshohocken, PA.

ASTM E562, Standard Test Method for Determining Volume Fraction by Systematic Manual Point Count, ASTM International, 2002. West Conshohocken, PA.

ASTM G48, Standard Test Methods for Pitting and Crevice Corrosion Resistance of Stainless Steels and Related Alloys by Use of Ferric Chloride Solution, ASTM International, 2009. West Conshohocken, PA.

BADESHIA, H.; HONEYCOMBE, R. Steels: Microestruture and Properties. $3^{\mathrm{a}}$ ed. Butterworth-Heinemann, 2006. United Kingdom

BAI, G. et al. Intergranular corrosion behavior associated with delta-ferrite transformation of Ti-modified Super304H austenitic stainless steel. Corrosion Science, v. 90, p. 347-358, 2015 .

BROOKS, J.A; THOMPSON, A.W; WILLIANS, J.C. A fundamental study of the benefical effects of delta ferrite in reducing weld cracking. Welding Journal, 1984.

FUJII, Tomoyuki et al. Crystallography of intergranular corrosion in sensitized austenitic stainless steel. Materials Characterization, v. 144, p. 219-226, 2018.

GONÇALVES, R.B; PARANHOS, R. P. R; TERRONES L.A.H. Efeito do Tratamento Térmico de Solubilização e Estabilização na microestrutura de uma Junta Soldada com Aço Inox 347. Matéria, 2017 Rio de Janeiro, v.22, n.1.

GONZAGA, A.C; BARBOSA, C; TAVARES, S.S.M; ZEEMANN, A; PAYÃO, J.C. Influence of post welding heat treatments on sensitization of AISI 347 stainless steel welded joints. Journal of Materials Research and Technology, 2020 p. v.9, n 3, p. 908-921.

LIPPOLD, J. C.; KOTECKI, D. J. Welding Metallurgy and Weldability of Stainless Steels. John Wiley \& Sons, 2005. New Jersey.

Persp. Online: exatas \& eng., Campos dos Goytacazes, 29 (10) $74-89-2020$

https://ojs3.perspectivasonline.com.br/ 
MALLICK, P. et al. Effect of cryogenic deformation on microstructure and mechanical properties of 304 austenitic stainless steel. Materials Characterization, v. 133, p. 77-86, 2017.

MODENESI, P.J. Soldabilidade dos Aços Inoxidáveis. Coleção Tecnologia da Soldagem. São Paulo, SENAI-SP, 2001. v. 1.

PASSOS, D. O.;OTUBO, J. A influência da ferrita delta em aços inoxidáveis austeníticos forjados. Rem: Rev. Esc. Minas [online]. 2010, vol.63, n.1 [cited 2020-04-20], pp.57-63.

PRICEPUTU I.L., MOISA B., CHIRAN A., NICOLESCU G., BACINSCHI Z. Delta Ferrite Influence In AISI 321 Stainless Steel Welded Tubes. The Scientific Bulletin of VALAHIA University MATERIALS and MECHANICS, 2009.

RAJ, B.; KHATAK, H. S. Corrosion of Austenitic Stainless Steels: Mechanism, Mitigation and Monitoring. Woodhead Publishing Limited, 2002. India.

SEDRIKS, A. J. Corrosion of Stainless Steels. $2^{a}$ ed. John Wiley \& Sons, 1996. EUA

TAVARES, S; SOUZA, V; SOUZA, J. KINA, A. YAE, A. Influência dos Tratamentos Térmicos de Estabilização e Solubilização na Resistência a Corrosão Intergranular do Aço Inoxidável AISI 347 Fundido. Tecnologia em Metalurgia e Materiais, 2008. São Paulo, v.4, n.3, p. 18-22.

TOTTEN, G. E. Steel Heat Treatment Handbook Metallurgy And Technologies Vol. 2 ed. CRC Press, 2006.USA.

WANG, J. et al. Effect of $\delta$-ferrite on the stress corrosion cracking behavior of 321 stainless steel. Corrosion Science, v. 158, p. 108079, 2019.

Persp. Online: exatas \& eng., Campos dos Goytacazes, 29 (10) $74-89$ - 2020 